\title{
Hyperbranched polyester polyol modified with polylactic acid as a compatibilizer for plasticized tapioca starch/polylactic acid blends
}

\author{
Ricardo Mesias ${ }^{1}$ and Edwin Murillo2* \\ ${ }^{1}$ Grupo de Investigación materiales poliméricos, Universidad de Antioquia, Medellín, Colombia \\ ${ }^{2}$ Grupo de Investigación en Materiales Poliméricos (GIMAPOL), Departamento de Química, \\ Universidad Francisco de Paula Santander, San José de Cúcuta, Colombia \\ *edwinalbertomr@ufps.edu.co
}

\begin{abstract}
A hyperbranched polyester polyol of the second generation (HBP2) was modified with polylactic acid (HBP2-g-PLA) and employed as a compatibilizer for plasticized tapioca starch (TPS)/polylactic acid (PLA) blends. The effect of the compatibilizer HBP2-g-PLA was evaluated in comparison to the control sample (TPS/PLA blend without HBP2- $g$-PLA). The torque value of the TPS/PLA blends with HBP2-g-PLA was lower than that of the control sample, while thermal stability and crystallinity followed opposite behavior. The glass transition temperature $\left(\mathrm{T}_{\mathrm{g}}\right)$ and degree of crystallinity of the TPS/PLA blends with HBP2-g-PLA decreased with increasing mass fraction of HBP2-g-PLA. By scanning electron microscopy (SEM), it was observed that the morphology of the TPS/PLA blends with HBP2-g-PLA was more homogeneous than that of the control sample, confirming that HBP2- $g$-PLA acted as a compatibilizer and plasticizing agent to the TPS/PLA blends. Rheological analysis of the compatibilized TPS/PLA blends indicated the presence of microstructure.
\end{abstract}

Keywords: biodegradable polymers, hyperbranched polyester, compatibilization, thermoplastic starch/PLA blend, properties.

\section{Introduction}

The environmental impact caused by conventional non-biodegradable polymeric materials waste has created the need to develop sustainable polymeric materials from renewable resources, since alternative methods of recycling and disposal of non-biodegradable polymeric materials have not been fully effective ${ }^{[1,2]}$. Petrochemical resources are non-renewable and are continuously depleted, so it is important to find sustainable substitutes; especially for disposable packaging applications with a short time of use $\mathrm{e}^{[3]}$.

The starch has granular form and it is not a thermoplastic polymer. Therefore, for obtaining thermoplastic starch, it has to be plasticized $d^{[4,5]}$. The typically used plasticizing agents are hydrophilic. Some of these are urea, ethanolamine, glycerol and sorbitol ${ }^{[6]}$. The material obtained has poor mechanical properties as compared to polymers derived from petrochemical sources ${ }^{[1,6]}$. One way to improve mechanical properties and maintain the biodegradability properties consists in mixing starch with PLA, which is hydrophobic, biodegradable, and it has good processability and mechanical properties (high tensile modulus and tensile strength) ${ }^{[7,8]}$. The incompatibility of the hydrophobic aliphatic polyesters (for example PLA) and starch makes a weak adhesion between the two components $^{[3]}$, which results in low mechanical properties of this mixture ${ }^{[9,10]}$. In order to improve compatibility between the two phases and the physicochemical properties of the starch/PLA blends, different strategies of compatibilization have been developed ${ }^{[9,11]}$. PLA/starch modified with maleic

anhydride (starch- $g$-MA) blends were prepared, however, they exhibited poor interfacial adhesion, which was due to the hydrophobicity of PLA and the hydrophilicity of starch- $g-\mathrm{MA}^{[10]}$. PLA was blended with starch, plasticized with glycerol, and the morphology of the materials obtained was very coarse (TPS particles sizes between 5 and $30 \mu \mathrm{m}$ ). But when PLA was replaced with PLA modified with MA (PLA- $g$-MA) the particle size was in the $1-3 \mu \mathrm{m}$ range $\mathrm{e}^{[12]}$. Starch/PLA blends were obtained by using epoxidized soybean oil (ESO) as a reactive compatibilizer agent. The starch granules were grafted with MA to enhance its reactivity with ESO. The blends prepared were compatible ${ }^{[13]}$. Starch/PLA blends were obtained employing three strategies of compatibilization: 1. Formation of urethane bonds in-situ, 2. Crosslinking between starch and PLA, and 3. Addition of PLA grafted amylose. Better results were obtained by using PLA grafted amylose as compatibilizer agent ${ }^{[3]}$.

The hyperbranched polyester polyols (HBP) possess structures with a high structural packing and great number of OH groups. They also have low viscosity in solution and molten state, a lower degree of molecular entanglements than linear polymers of the same molar mass, and they are not toxic ${ }^{[14-21]}$. These materials may be a good alternative to obtain compatibilizer agents by modification of $\mathrm{OH}$ groups with other compounds such as amine, isocyanate, acids, etc. In a previous study ${ }^{[2]}$, HBP2 was modified with different proportions of PLA to obtain materials (for example, HBP2-g-PLA) that may be employed for studies of the 
compatibilization of starch/PLA blends, since there are $\mathrm{OH}$ and PLA units on the periphery of this material. Additionally, this material has low viscosity (lower than 1 Pa.s) due to small hydrodynamic dimensions in solution and possibly it may be located at the interface between starch and PLA ${ }^{[2]}$. Thus, HBP2-g-PLA possibly acts as a plasticizing agent to this blend.

As was already mentioned, the materials usually employed for the compatibilization of starch/PLA blends are linear structures with low functionality. However, taking the structure of HBP2- $g$-PLA into account ${ }^{[21]}$, this material may possibly act as a compatibilizer agent for TPS/PLA blends, since PLA and OH groups of HBP2- $g$-PLA can interact with PLA as well as TPS, respectively (Figure 1).

In order to make effective compatibilization of the TPS/PLA blends, HBP2-g-PLA may be used as a new alternative. Therefore, the aim of this study was to evaluate the compatibilizer effect of HBP2- $g$-PLA in a TPS/PLA blend $(50 / 50 \mathrm{wt} \%)$. Furthermore, the structure to properties relationship was investigated for different proportions of HBP2- $g$-PLA and TPS/PLA blends considering their structural, thermal, rheological, morphological and mechanical properties. Additionally, in this study the neat PLA was not processed under the same condition of the TPS/PLA blends.

\section{Experimental Part}

\section{1 Materials}

The PLA with the number average molar mass $\left(\mathrm{M}_{\mathrm{n}}\right)$ $68.000 \mathrm{~g} / \mathrm{mol}$ and acid value of $51.72 \mathrm{mg} \mathrm{KOH} / \mathrm{g}$ was supplied by the company ALICO from Colombia. TPS (Plasticized tapioca starch) was previously prepared in our laboratory (60 wt $\%$ of tapioca starch and $40 \mathrm{wt} \%$ of sorbitol) by using a torque rheometer Thermo Science at $150{ }^{\circ} \mathrm{C}$ and rotation speed of $50 \mathrm{rpm}$. HBP2- $g$-PLA was synthesized as described in a previous study ${ }^{[21]}$ by an esterification reaction, employing 45 wt \% of HBP2 and $55 \mathrm{wt} \%$ of $\mathrm{PLA}^{[21]}$. In that work ${ }^{[21]}$, this material was named HBP2G45 and the characteristics are as follows: acid value: $8.99 \mathrm{mg} \mathrm{KOH} / \mathrm{g}$, hydroxyl value: $172.48 \mathrm{mg} \mathrm{KOH} / \mathrm{g}$, decomposition temperature $\left(\mathrm{T}_{\mathrm{d}}\right)$ : $243.1{ }^{\circ} \mathrm{C}$ and $\mathrm{T}_{\mathrm{g}}: 42.8{ }^{\circ} \mathrm{C}^{[21]}$.

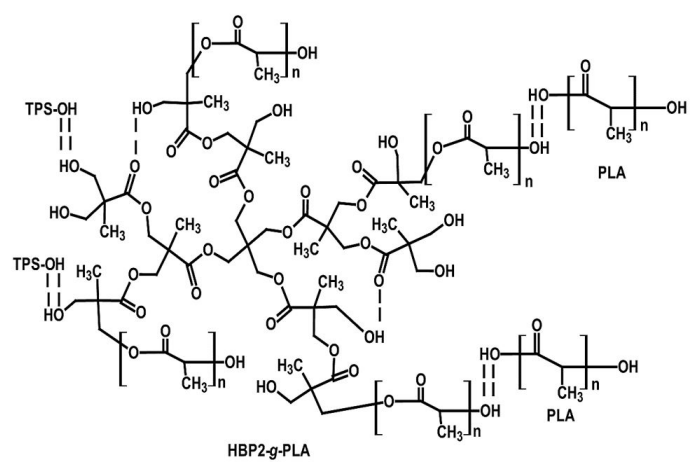

Figure 1. Schematic representation of the interactions of TPS and PLA with the HBP2-g-PLA.

\subsection{Preparation of the samples}

The respective proportions of TPS, PLA and HBP2-g-PLA were weighed and homogenized in a container, and measured by torque rheometer Thermo Science at $200^{\circ} \mathrm{C}$. The rheometer was kept at a rotation speed of $50 \mathrm{rpm}$. The mixing time was 5 min. In all cases the mass ratio of TPS and PLA was $50 / 50 \mathrm{wt} \%$. The amount of HBP2-g-PLA utilized were $5 \mathrm{wt} \%$ (Blend 1 ), $10 \mathrm{wt} \%$ (Blend 2 ), $15 \mathrm{wt} \%$ (Blend 3 ) and $20 \mathrm{wt} \%$ (Blend4) with respect to the total amount of TPS and PLA. To evaluate the compatibilizing efficiency of the HBP2- $g$-PLA in the TPS/PLA blends, a control blend (TPS/PLA 50/50 wt \%) without HBP2-g-PLA was prepared under the same conditions used for preparation of TPS/PLA blends with HBP2-g-PLA.

\subsection{Characterization}

The thermal stability of the samples was evaluated by thermogravimetric analysis (TGA) on a TA Instruments model Q-500 employing nitrogen atmosphere. The materials (around $20 \mathrm{mg}$ ) were heated from room temperature to $600{ }^{\circ} \mathrm{C}$, utilizing a heating rate of $10^{\circ} \mathrm{C} / \mathrm{min}$. Differential scanning calorimetry (DSC) measurements were performed on a TA Instruments model Q100 equipped with a cooling and heating system. The samples (around $10 \mathrm{mg}$ ) were heated at a heating rate of $40{ }^{\circ} \mathrm{C} / \mathrm{min}$ from room temperature to $250^{\circ} \mathrm{C}$, followed by an isotherm for $5 \mathrm{~min}$. The sample was then cooled to $-80^{\circ} \mathrm{C}$, using a cooling rate of $40^{\circ} \mathrm{C} / \mathrm{min}$ and equilibrated at $-80^{\circ} \mathrm{C}$ (first scan). The second heating scan was in the temperature range between $-80{ }^{\circ} \mathrm{C}$ to $250^{\circ} \mathrm{C}$ by using a heating rate of $20^{\circ} \mathrm{C} / \mathrm{min}$. In all cases a nitrogen atmosphere was used. The $\mathrm{T}_{\mathrm{g}}$, melting temperature $\left(\mathrm{T}_{\mathrm{m}}\right)$ and melting enthalpy $\left(\Delta \mathrm{H}_{\mathrm{m}}\right)$ were determined from the second heating scan. The samples (granules) for $\mathrm{X}$ ray diffraction (XRD) analysis were placed in a desiccator for $24 \mathrm{~h}$. The XRD analysis was performed on a PANalytical X'Pert PRO MPD diffractometer by using $\mathrm{Cu}-\mathrm{K}$ alpha radiation $(\lambda=1.5406 \AA)$. The voltage and operating current were $45 \mathrm{kV}$ and $40 \mathrm{~mA}$, respectively. The sweep was done between 10 and 70 degrees with steps of 0.013 degrees and a step time of $59 \mathrm{~s}$. The samples for SEM analysis were placed in a desiccator for $24 \mathrm{~h}$. They were then fractured under liquid nitrogen, and finally were coated with gold. SEM analysis was done using a microscope JEOL JSM-6490LV at an acceleration voltage of $5 \mathrm{kV}$. In order to perform rheological analysis, a rotational rheometer of Malvern Instruments was employed, using a cone-plate geometry with a constant gap setting of $1 \mathrm{~mm}$. The oscillatory analysis was performed by using strain of $0.01 \%$ at angular frequency between 0.1 and $100 \mathrm{~Hz}$. All measurements were performed at $200^{\circ} \mathrm{C}$. For tensile analysis the type IV specimens were prepared in an Implejoy injection machine. About $25 \mathrm{~g}$ sample was put into the cylinder for $5 \mathrm{~min}$. and kept at $200{ }^{\circ} \mathrm{C}$ and then molded by using a piston. The mechanical properties according to ASTM D 638 standard were determined on a universal machine brand Digimess at a deformation rate of $5 \mathrm{~mm} / \mathrm{min}$.

\section{Results and Discussions}

Figure 2 presents the torque vs time graph (Figure 2a) and the temperature vs time graph (Figure $2 b$ ). It can be observed (Figure 2a), that all the samples exhibited an increase in torque value after the first minute of mixing 

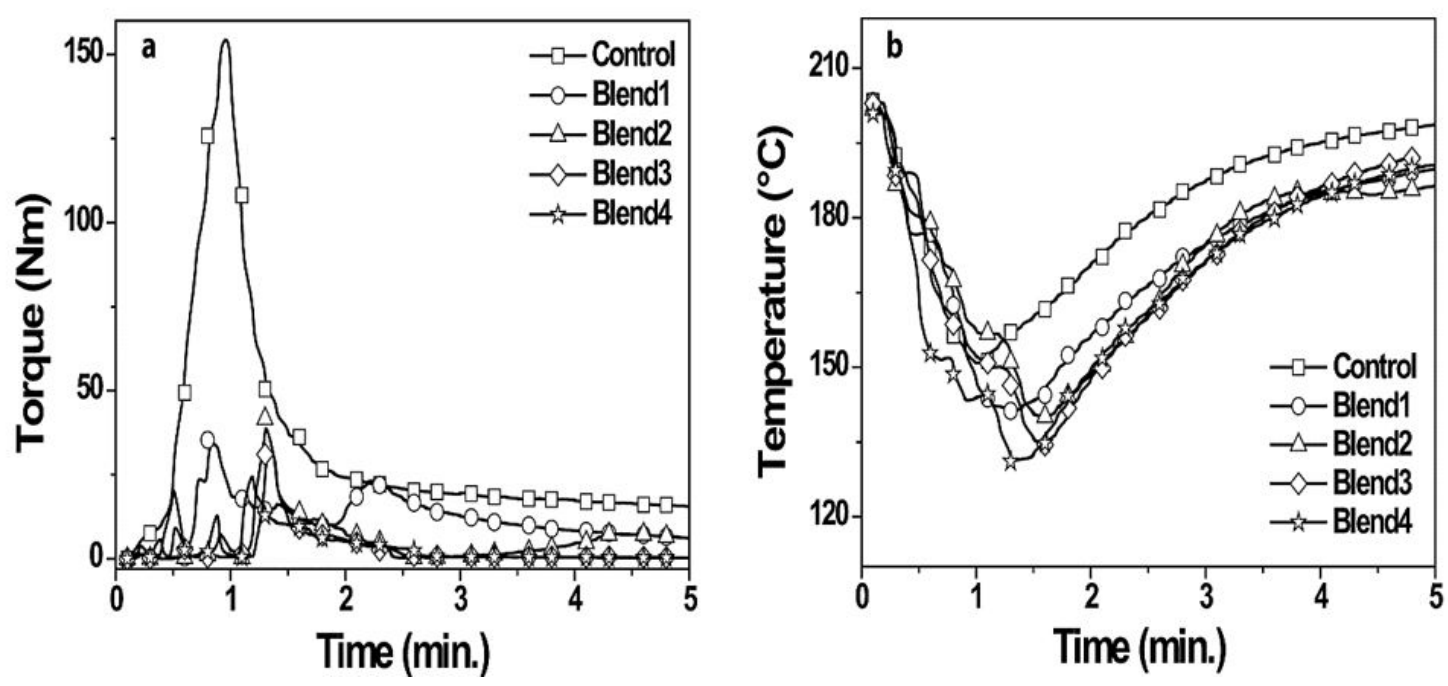

Figure 2. Torque rheometry of the TPS/PLA blends and control sample: (a) torque vs time, (b) temperature vs time.

process. The control sample showed the highest torque value (156.4 Nm) indicating the highest viscosity of all samples. The TPS/PLA blends with HBP2-g-PLA exhibited much lower torque value in comparison to the control sample; this observation implies the plasticizing effect of HBP2- $g$-PLA on the TPS/PLA blends. In all cases, the torque stabilized at about 4.5 min of mixing, which can be taken as the optimum mixing time. The first increase of the torque is due to the melting process of the sample. The second increase on the torque value is possibly due to increase of interactions and rearrangement of the TPS. It was observed that the second increase on torque value reached a stable value, therefore the degradation process was not observed. The second increase on torque value due to the Blend1 appeared after two minutes. It is possibly attributed to a low proportion of the HBP2-g-PLA, which was employed during the preparation of this blend, since there is low interactions and rearrangement of the starch granules.

The final torque values did not exceed $50 \mathrm{Nm}$. The final torque values obtained for blends of PLA/thermoplastic acetylated starch $(5-10 \mathrm{Nm})^{[1]}$, are comparable to that of the Blend1 (5.90) Nm) and Blend2 (5.58. Nm), but are higher than those of the Blend3 $(2.6 \mathrm{Nm})$ and Blend4 $(2.3 \mathrm{Nm})$. All blends reduced the initial temperature gradually (Figure 2b). The control sample showed a reduction in temperature with respect to the TPS/PLA blends with HBP2-g-PLA, indicating that the presence of HBP2-g-PLA required an additional energy to melt. Therefore, an increase in torque (Figure 2a) is a result of not completely melted samples, which is also reflected in reduced sample temperature. These results are important because the processing temperature of TPS/PLA blends with HBP2-g-PLA is reduced as compared to the control sample.

TGA and DSC thermograms of samples are presented in Figure 3, while the $\mathrm{T}_{\mathrm{d}}$ values of the samples, obtained at $10 \%$ of weight loss, are presented in Table 1. Figure $3 \mathrm{a}$ and $3 \mathrm{~b}$ show the TGA thermograms of the samples. TPS shows a small weight loss $(8.18 \%)$ between 100 and $200{ }^{\circ} \mathrm{C}$ and this can be attributed to evaporation of water due to the
Table 1. Values of $\mathrm{T}_{\mathrm{g}}, \mathrm{T}_{\mathrm{m}}$ and $\mathrm{T}_{\mathrm{d}}$ of the samples.

\begin{tabular}{cccccc}
\hline Sample & $\mathbf{T}_{\mathbf{d}}\left({ }^{\circ} \mathbf{C}\right)$ & $\mathbf{T}_{\mathrm{g}}\left({ }^{\circ} \mathbf{C}\right)$ & $\mathbf{T}_{\mathbf{m}}\left({ }^{\circ} \mathbf{C}\right)$ & $\begin{array}{c}\Delta \mathbf{H}_{\mathbf{m}} \\
(\mathbf{J} / \mathbf{g})\end{array}$ & $\mathbf{X}_{\mathbf{c}}(\%)$ \\
\hline TPS & 264 & 26.1 & -- & - & - \\
Control & 301 & 59.6 & 153.1 & 2.6 & 5.6 \\
Blend1 & 289 & 57.4 & 152.1 & 2.5 & 5.4 \\
Blend2 & 285 & 49.8 & 150.8 & 1.0 & 2.2 \\
Blend3 & 280 & 48.0 & - & - & - \\
Blend4 & 281 & 43.3 & - & - & - \\
\hline
\end{tabular}

presence of humidity. Additionally, TPS shows another significant weight loss at $264{ }^{\circ} \mathrm{C}$. The thermal stability of the control sample is higher than that of the TPS/PLA blends with HBP2-g-PLA (Figures $3 a$ and $3 b$ ). This behavior can be attributed to low thermal stability of HBP2- $g$-PLA $\left(243.1^{\circ} \mathrm{C}\right)^{[21]}$ or a closer interaction between the TPS and PLA could facilitate faster PLA degradation. This also has been observed in starch/PLA blends using butyl-etherified wax as a compatibilizer agent ${ }^{[22]}$. Furthermore, some authors have demonstrated that TPS tends to reduce the thermal stability of PLA ${ }^{[22,23]}$, which is caused by the moisture.

The $\mathrm{T}_{\mathrm{d}}$ of the PLA on the TPS/PLA blends with HBP2-g-PLA was lower than that of neat PLA $\left(332^{\circ} \mathrm{C}\right)^{[21]}$, it can be attributed to the processing, since it has been demonstrated that the thermal stability of PLA is slightly reduced by processing. The mechanism of the degradation of PLA has been attributed to depolymerization by intramolecular transesterification and it occurs between 270 and $360{ }^{\circ} \mathrm{C}^{[24]}$.

The TGA thermograms did not exhibit the $\mathrm{T}_{\mathrm{d}}$ of the HBP2-g-PLA $\left(243.1^{\circ} \mathrm{C}\right)$ and this may be associated with the low amount of HBP2-g-PLA employed or the interactions of HBP2-g-PLA with other components in the blends. Additionally, the $\mathrm{T}_{\mathrm{d}}$ values of the TPS/PLA blends with HBP2-g-PLA do not show dependence on the amount of HBP2-g-PLA employed (up to $20 \mathrm{wt} \%$ ). This can be interpreted by differences in the degree of interaction between the materials (TPS, PLA and HBP2-g-PLA) or probably differences in degradation mechanisms ${ }^{[22,23]}$. The Blend3 

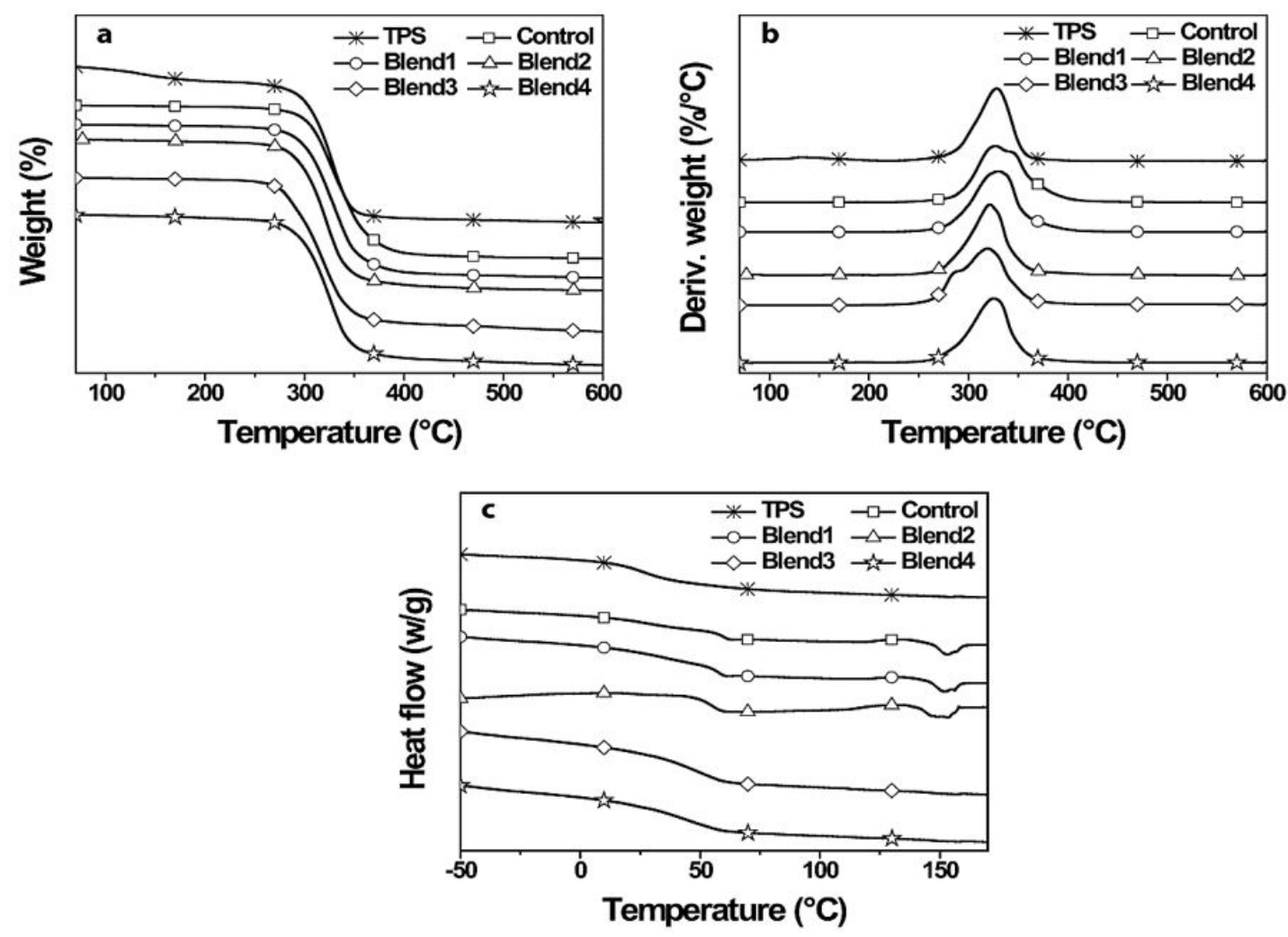

Figure 3. TGA and DSC Thermograms (a) Weight vs. temperature, (b) Deriv. weight vs. temperature, (c) Heat flow vs. temperature.

exhibited two peaks (Figure 3b); it is attributed possibly to the formation of some structure of low mass molar, which was formed by hydroxyl-ester interchange reaction, it has been reported for hyperbranched polyesters ${ }^{[19]}$.

DSC analysis was performed in order to identify thermal transitions and possible changes in $\mathrm{T}_{\mathrm{g}}$. The control sample exhibits a $\mathrm{T}_{\mathrm{g}}$ value of $59.6^{\circ} \mathrm{C}$ (Figure $3 \mathrm{c}$ ), which is higher than that of neat PLA $\left(57.6^{\circ} \mathrm{C}\right)^{[21]}$ and neat TPS $\left(26^{\circ} \mathrm{C}\right)$ meaning that TPS restricts mobility of PLA chains in this sample and that a new structural arrangement or interaction possibly occur. Additionally, it also may be due to the migration of sorbitol present in TPS. The $T_{g}$ value of the control sample is also higher than that of the TPS/PLA blends with HBP2-g-PLA, which follow the trend of an decrease with the HBP2-g-PLA content (Figure $3 \mathrm{c}$ and Table 1). In the case of the Blend 3 and Blend4, it is due to improved miscibility of the components ${ }^{[1]}$, because the PLA crystalline domains disappear. But in the case of blend 1 and Blend2, it is due to a plasticizing effect of HBP2- $g$-PLA, which is also supported by the lowest viscosity in the molten state (lower than $1 \mathrm{~Pa} . \mathrm{s})^{[21]}$ and by the torque rheometry study (Figure 1). A similar effect of starch/PLA blends was reported for $\mathrm{MA}^{[25]}$. Jang et al. ${ }^{[26]}$ observed a reduction of $\mathrm{T}_{\mathrm{g}}$ value of starch/PLA blends compatibilized with MA, but the variations were larger than $6^{\circ} \mathrm{C}$ in relation to neat PLA. The $\mathrm{T}_{\mathrm{g}}$ values are the lowest for Blend 3 and Blend 4 and allow to infer that these blends present the highest compatibilization degree and miscibility. The absence of the $\mathrm{T}_{\mathrm{g}}$ of the HBP2-g-PLA $\left(42.8^{\circ} \mathrm{C}\right)^{[21]}$ in the TPS/PLA blends thermograms, could not be observed due to the low difference between the $\mathrm{T}_{\mathrm{g}}$ values.

$\mathrm{T}_{\mathrm{m}}$ of the PLA in the control sample is lower than that of neat PLA $\left(156.7^{\circ} \mathrm{C}\right)^{[21]}$. Therefore, TPS reduces structural packing. $\mathrm{T}_{\mathrm{m}}$ of the control sample was slightly higher than those of the Blend1 and Blend2 (Table 1). Blend3 and Blend4 did not exhibit $\mathrm{Tbbb}_{\mathrm{m}}$, which indicates that these blends increased ostensibly the degree of structural disorder, since their crystalline nature was reduced. The conclusion to be drawn from these results is that the Blend 3 and Blend4 present a high compatibilization degree.

In a study of compatibilization of the starch/PLA blends three different strategies have been reported: a) in situ formation of urethane linkages; b) coupling with peroxide between starch and PLA, and (c) the addition of PLA-grafted amylose as a compatibilizer; in all cases the $\mathrm{T}_{\mathrm{m}}$ of the PLA was observed ${ }^{[3]}$.

The degree of crystallinity of the samples was determined by employing the following Equation $1^{[26]}$ :

$$
X_{c}=\left(\Delta H_{m} / \varnothing_{P L A}\right) / \Delta H_{m}^{0} \times 100
$$

Where $X_{c}, \Delta H_{m}, \varnothing_{P L A}$ and $\Delta H_{m}^{0}$ are the crystallinity percent, the melting enthalpy, the weight fraction of PLA in the blends and the melting enthalpy of a crystal of infinite size of PLA $(93.6 \mathrm{~J} / \mathrm{g})$ respectively ${ }^{[3]}$. The degree of crystallinity of the samples was calculated as a function of PLA content. The control sample showed higher degree of crystallinity than the TPS/PLA blends with HBP2-g-PLA (Table 1). 
Among the TPS/PLA blends with HBP2-g-PLA, Blend1 with the lowest amount of HBP2-g-PLA showed the highest values of $\Delta H_{m}$, and $X_{c}$, which indicates that this sample has a greater number of crystals (Table 1). HBP2-g-PLA thus affected the crystallinity of the PLA in the TPS/PLA blends enormously. This is possibly attributed to HBP2-g-PLA, which restricts the structural packing of the PLA, and since it is an amorphous molecule, it increases the molecular disorder in PLA. According to the literature reviewed, we could not find evidence for any similar case, where the $T_{m}$ of TPS/PLA or starch/PLA blends did not appear. This is important because it allows concluding that HBP2- $g$-PLA may be a good alternative for the compatibilization of starch/PLA or TPS/PLA blends ${ }^{[27]}$.

Figure 4 shows the XRD patterns of the neat TPS and PLA, control sample and TPS/PLA blends (with HBP2-g-PLA). TPS exhibits a wide peak between $2 \theta=12.5$ and $30^{\circ}$; it is associated with the $\mathrm{C}$ type crystallinity present in TPS ${ }^{[5]}$. In this $2 \theta$ range, the peak can be also attributed to $\mathrm{V}$ type crystallinity $\left(2 \theta=21^{\circ}\right)$, which has been identified for starch plasticized with ethanolamine ${ }^{[28]}$ and glycero ${ }^{[29]}$. In the control sample, the intensity of this peak is appreciably reduced, indicating that in the TPS/PLA blends with HBP2- $g$-PLA some degree of interaction between these materials exists (TPS, HBP2-g-PLA, sorbitol and PLA). Neat PLA exhibits peaks at $2 \theta=16.8^{\circ}, 19.5^{\circ}$ and $22.3^{\circ}$, which are associated with the $\alpha$ crystalline system ${ }^{[30,31]}$. In the case of the TPS/PLA blends with HBP2- $g$-PLA, the PLA peak intensities decreased significantly. Blend2, Blend 3 and Blend 4 exhibited peaks at $2 \theta=16.8$ and $19.5^{\circ}$, but the peak at $22.3^{\circ}$ was not observed. These results are in accordance to those of DSC analysis, since it has been shown that the degree of crystallinity of these materials is reduced as compared to the control sample. Furthermore, it confirms once more that HBP2- $g$-PLA is a good compatibilizer agent to TPS/PLA blends, especially when it is used in proportions of 15 and $20 \mathrm{wt} \%$ (the lowest crystallinity of PLA and significant lowering of $\mathrm{T}_{\mathrm{g}}$ value).

Figure 5 shows the SEM micrographs of the cryofractured samples. TPS exhibits a homogenous surface (Figure 5a), while the control sample (Figure 5b) presents a discontinuous phase with rounded structures, which is attributed to the

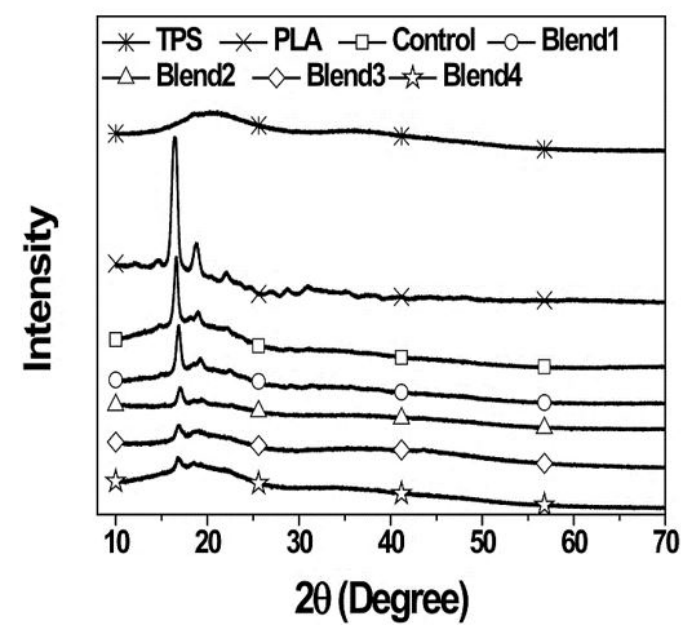

Figure 4. Difractograms of the samples. starch granules. Hypothetically, this is attributed to possible migration of sorbitol, employed as plasticizing agent for starch, to PLA or interface. In addition, cracks were observed in the control sample, which indicates a fragile fracture of this sample. The same behavior was exhibited by blends of PLA with maleate $\operatorname{starch}^{[30]}$, acetylated $\operatorname{starch}^{[1]}$ and corn $\operatorname{starch}^{[32]}$.

Blend1 (Figure 5c) shows the presence of a discontinuous phase with fractured zones in the interface and in the starch granules, which suggests limited miscibility of the components. Blend2 (Figure 5d) presents a homogeneous phase with fractures due to the presence of fine pores, which were due to the presence of volatile compounds that evaporated by the application of a vacuum. Compatibility of Blend2 (Figure 5d) is better than that of Blend1 (Figure 5c), since the fractured starch granules are not observed. Figure 5e (Blend3) shows a homogeneous phase in the presence of starch granules and fragments displayed on the surface, which could be due to tearing the matrix during sample preparation. Nevertheless, it shows good homogeneity. Blend4 (Figure 5e) presents a slight fracture at the interface, but this sample shows good homogenization. Furthermore, no domains were observed for this sample. These results are consistent with the DSC analysis and it can be concluded that the TPS/PLA blends with HBP2-g-PLA show good homogeneity and that HBP2-g-PLA exhibits a good compatibilizer effect on TPS/PLA blends.

In the starch/PLA blends, compatibilized with MA(3 wt $\%$ ) and maleated thermoplastic starch $(5,10$ and $15 \mathrm{wt} \%)$, domains of starch and PLA were observed. All blends exhibited cavities $^{[33]}$. Therefore, all these blends were immiscible. In another study, it was observed for corn TPS/PLA blends that dispersion between the two phases (TPS and PLA) increased with increasing formamide content ${ }^{[34]}$. The same was evidenced when citric acid was used as a compatibilizer agent to TPS/PLA blends ${ }^{[35]}$. The control sample, Blend3 and Blend4 were selected for rheological measurements to study the plasticizing effect of HBP2- $g$-PLA in these blends. Both TPS/PLA blends have the best compatibilization degree, the lowest crystallization degree of PLA and lower $\mathrm{T}_{\mathrm{g}}$ value as compared to the control sample.

The rheological behavior of the blends is presented in Figure 6. For all samples a reduction of complex viscosity (Figure 6a) with the increasing angular frequency can be observed (pseudoplastic behavior), which is attributed to interaction rupture and disentanglement of the chains. The complex viscosity decreases with increased HBP2-g-PLA content meaning that HBP2-g-PLA acts as a plasticizing agent for these blends, which can be supported by the highest viscosity exhibited by the control sample in the range of angular frequency studied. In a recent study, TPS/PLA blends exhibited a Newtonian behavior between 1 and $10 \mathrm{~Hz}$, which was attributed to lower extent of interaction and entanglement of these blends ${ }^{[1]}$. Rheological results are in accordance with those obtained by torque rheometry. The reduction in viscosity of the TPS/PLA blends with HBP2-g-PLA facilitates the processability of the materials. The complex viscosity of the samples showed first a decrease and then an increase at different angular frequency values, for control sample at $100 \mathrm{~Hz}$, Blend 3 at $31.62 \mathrm{~Hz}$ and Blend4 at $25.2 \mathrm{~Hz}$ (Figure 6a). This is ascribed to the formation of a microstructure, which is able to deform elastically when it 

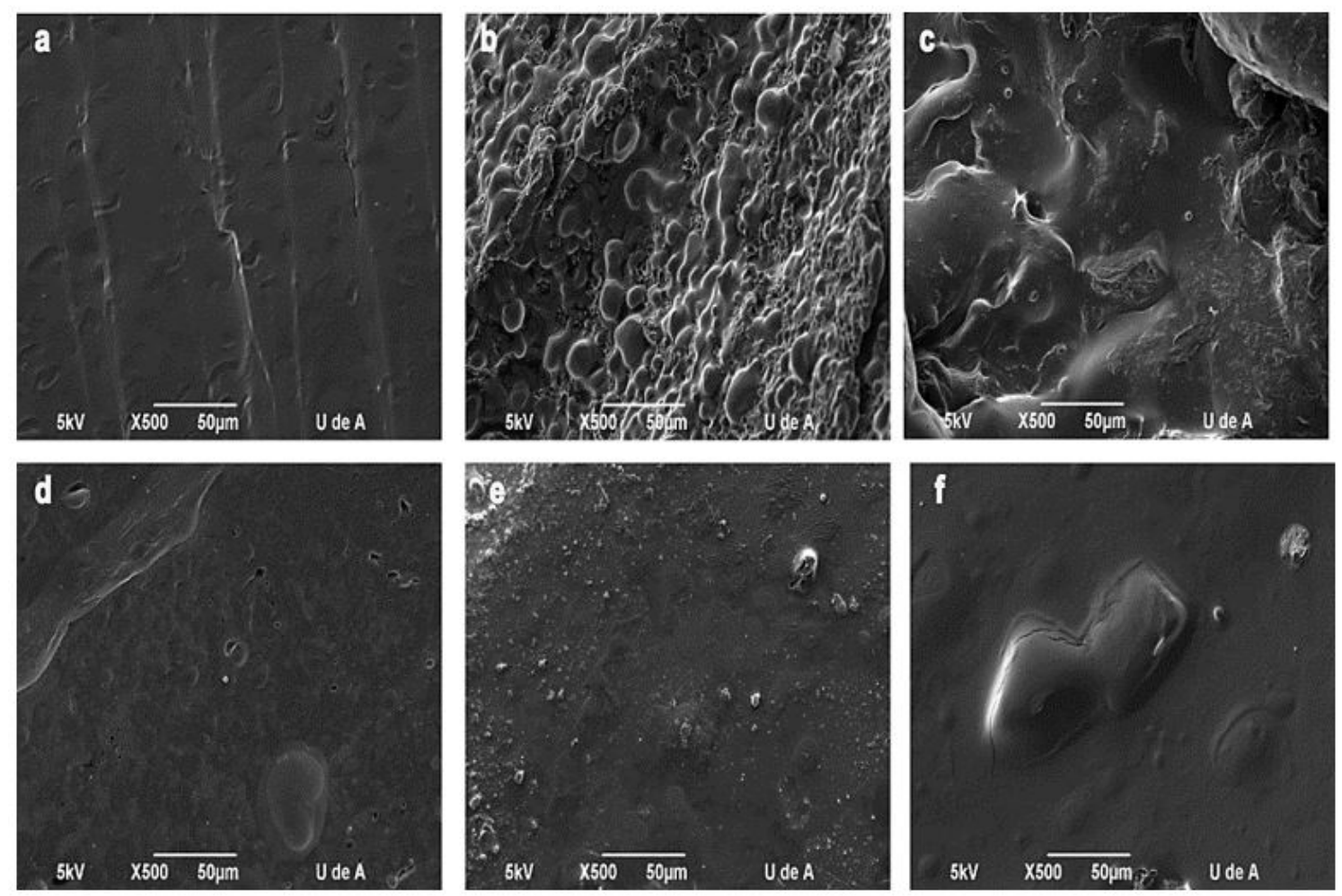

Figure 5. SEM micrographs of the samples: (a) TPS, (b) Control sample, (c) Blend1, (d) Blend2, (e) Blend3, (f) Blend4.
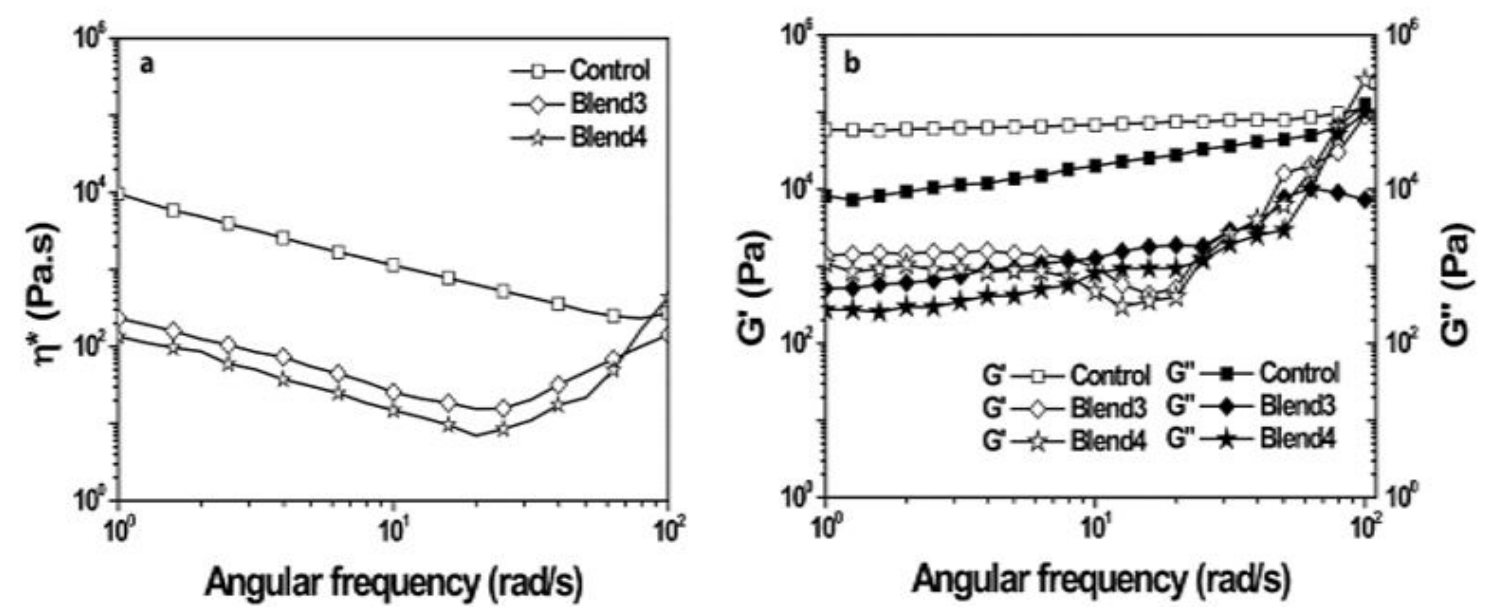

Figure 6. Rheological behavior of the control sample, Blend3 and Blend4: (a) complex viscosity vs. angular frequency, (b) G' and G” vs. angular frequency.

is exposed to external stress. This process has already been observed by several authors and is attributed to the formation of strong interactions ${ }^{[14,36]}$. It is worth noting that the control sample exhibited a higher value of angular frequency at the beginning of an increase of complex viscosity than those for Blend 3 and Blend4 (Figure 6a). Therefore, it can be inferred that the presence of HBP2-g-PLA favored the formation of microstructure, which is most probably due to onset of interactions between TPS, HBP2- $g$-PLA and PLA, which is corroborated by faster formation of microstructure in Blend4 (20 wt\% HBP2-g-PLA) than Blend3 (15 wt $\%$ HBP2-g-PLA).

Figure $6 \mathrm{~b}$ shows behavior of elastic (G') and viscous (G") moduli of the control sample, Blend3 and Blend4. The behavior of the control sample was viscoelastic with a predominant elastic contribution in contrast to the TPS/PLA blends with HBP2-g-PLA with higher viscous contribution. Namely, the transition from elastic to viscous behavior (G'< G') was not observed for the control sample. It is possible that this transition occurs at an angular frequency 

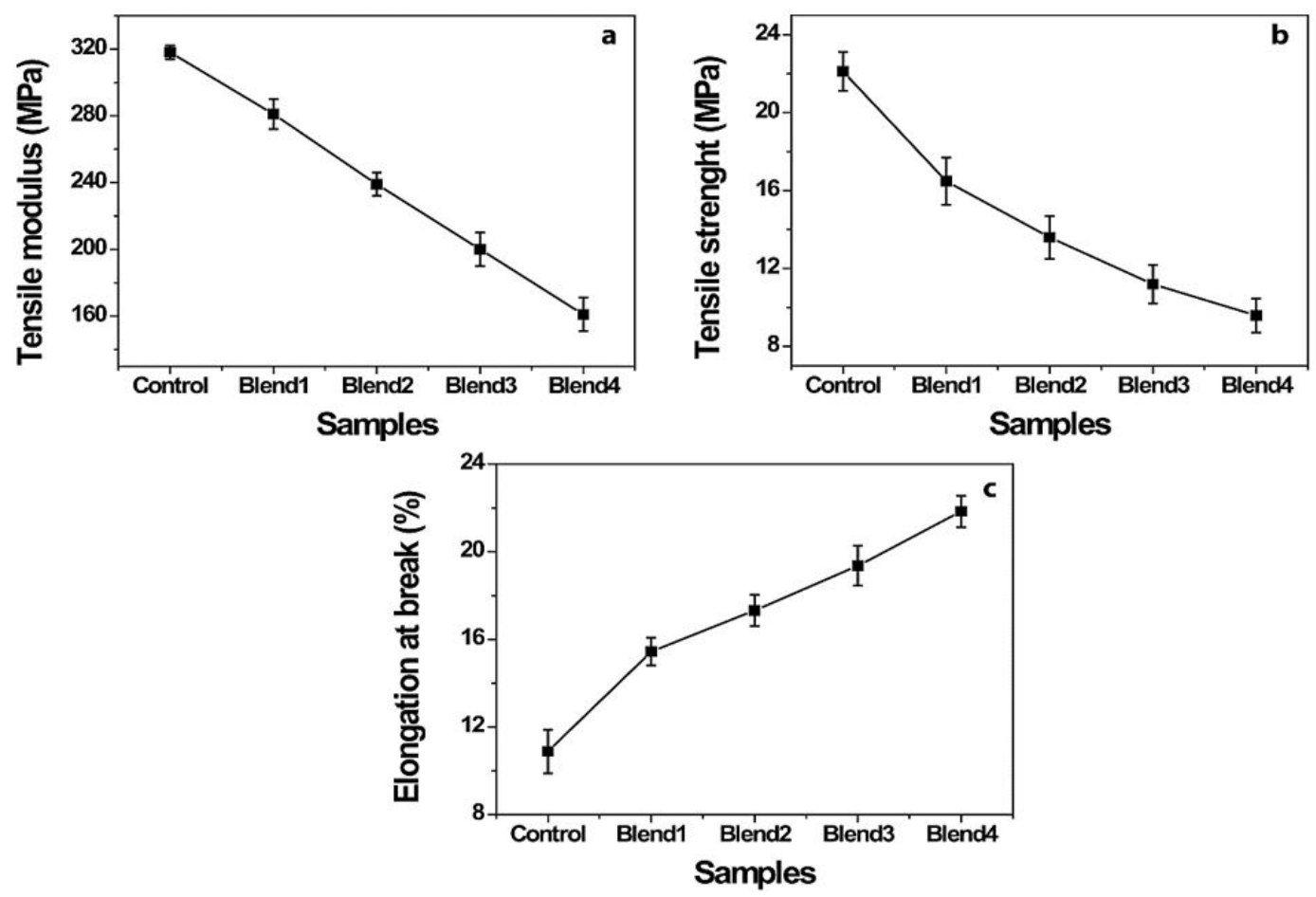

Figure 7. Mechanical properties of the samples: (a) Tensile modulus, (b) Tensile strength, (c) elongation at break.

higher than $100 \mathrm{~Hz}$. Thus Blend3 and Blend4 exhibit more viscous rheological behavior as compared to the control sample, due to plasticizing effect of the HBP2-g-PLA. Additionally, in Figure 6b, two transitions can be observed for the Blend 3 and Blend4. The first one corresponds to the transition from elastic to viscous response, and the second one from viscous to elastic response. This result confirms the formation of a microstructure, which is able to deform elastically and therefore supports the explanation presented above.

The tensile modulus (Figure 7a) and tensile strength (Figure 7b) of the control sample was higher than those of the TPS/PLA blends with HBP2-g-PLA. The tensile modulus and tensile strength of the blends decreased while the elongation at break increased with the proportion of the HBP2-g-PLA (Figure 7c) indicating a reduction of crystalline phase and increasing mobility of the chains. These results are in accordance with those obtained by DSC analysis, where the $\mathrm{T}_{\mathrm{g}}$ was also reduced with the proportion of HBP2$g$-PLA. The value of tensile modulus of the control sample is similar to that of the TPS/PLA blends compatibilized with PLA-grafted amylose $(340 \mathrm{MPa})^{[3]}$. The values of tensile strength obtained in this study are comparable with those obtained for compatibilized TPS/PLA (50/50), whose values were between 10 and $20 \mathrm{MPa}^{[9]}$. The elongation at break values of the samples are higher than those of the compatibilized TPS/PLA blends (lower than 10\%), which were compatibilized employing benzoyl peroxide, 4,4-methylenbis (phenyl isocyanate) and PLA-grafted amylose ${ }^{[3]}$.

\section{Conclusions}

This study makes an important contribution to the art state of these materials. The thermal stability of the TPS/PLA blends with HBP2- $g$-PLA did follow a trend with the proportion of HBP2-g-PLA employed. DSC analysis showed that Blend1 and Blend2 presented a $\mathrm{T}_{\mathrm{m}}$ and $\mathrm{T}_{\mathrm{g}}$, but Blend 3 and Blend 4 only exhibited $\mathrm{a} \mathrm{T}_{\mathrm{g}}$. The reduction on $\mathrm{T}_{\mathrm{g}}$ value of the blends with the content of HBP2-g-PLA is an indication that HBP2- $g$-PLA acts as plasticizing agent. XRD analysis showed that for the TPS/PLA blends with HBP2-gPLA, the peak of PLA associated to $\alpha$ crystallinity reduced its intensity. The rheological behavior of the Blend 3 and Blend4 was pseudoplastic. Furthermore, the flow behavior of the control sample was more elastic than those of the TPS/ PLA blends with HBP2- $g$-PLA. The use of HBP2- $g$-PLA as compatibilizer agent of the blends of TPS/PLA $(50 / 50 \mathrm{wt} \%)$ evidently changed rheological behavior of these blends.

We have demonstrated that HBP2-g-PLA can act as plasticizing and compatibilizer agent for the TPS/PLA blends. Conventional compatibilizer agents traditionally employed for the compatibilization of TPS/PLA blends, act only as compatibilizer agents. Furthermore the compatibilization degree is usually low. Therefore, according to the results obtained in this study, HBP2-g-PLA may be an alternative for compatibility of TPS/PLA blends.

\section{References}

1. Kun-yu, Z., Xiang-hai, R., Yu-gang, Z., Bin, Y., \& Li-song, D. (2009). Blends of poly (lactic acid) with thermoplastic acetylated starch. Chemical Research in Chinese Universities, 25, 
748-753. Retrieved in 2016, July 26, from http://59.72.0.32/ hxyj/CN/abstract/abstract12111.shtml\#.

2. Cai, J., Cai, C., Man, J., Zhou, W., \& Wei, C. (2014). Structural and functional properties of C-type starches. Carbohydrate Polymers, 101, 289-300. http://dx.doi.org/10.1016/j. carbpol.2013.09.058.

3. Schwach, E., Six, J.-L., \& Avérous, L. (2008). Biodegradable blends based on starch and poly(lactic acid): comparison of different strategies and estimate of compatibilization. Journal Polymer Environment, 16(4), 286-297. http://dx.doi. org/10.1007/s10924-008-0107-6.

4. Lu, D. R., Xiao, C. M., \& Xu, S. J. (2009). Starch-based completely biodegradable polymer materials. Express Polymer Letters, 3(6), 366-375. http://dx.doi.org/10.3144/ expresspolymlett.2009.46.

5. Guzmán, M., \& Murillo, E. A. (2015). The properties of blends of maleic-anhydride-grafted polyethylene and thermoplastic starch using hyperbranched polyester polyol as a plasticizer. Polymer Engineering and Science, 55(11), 2526-2533. http:// dx.doi.org/10.1002/pen.24143.

6. Yang, J. H., Yu, J. G., \& Ma, X. F. (2006). Study on the properties of ethylenebisformamide and sorbitol plasticized corn starch (ESPTPS). Carbohydrate Polymers, 66(1), 110116. http://dx.doi.org/10.1016/j.carbpol.2006.02.029.

7. Ke, T., \& Sun, X. S. (2003). Starch, Poly(lactic acid), and Poly(vinyl alcohol) Blends. Journal of Polymers and Environment, 11(1), 7-14. http://dx.doi.org/10.1023/A:1023875227450.

8. Jun, C. L. (2000). Reactive blending of biodegradable polymers : PLA and starch. Journal of Polymers and the Environment, 8(1), 33-37. http://dx.doi.org/10.1023/A:1010172112118.

9. Leadprathom, J., Suttiruengwong, S., Threepopnatkul, P., \& Seadan, M. (2010) Compatibilized polylactic acid/thermoplastic starch by reactive blend. Journal of Metals, Materials and Minerals, 20, 87-90. http://dx.doi.org/10.1155/2010/287082.

10. Yang, Y., Tang, Z., Xiong, Z., \& Zhu, J. (2015). Preparation and characterization of thermoplastic starches and their blends with poly(lactic acid). International Journal of Biological Macromolecules, 77, 273-279. PMid:25840151. http://dx.doi. org/10.1016/j.ijbiomac.2015.03.053.

11. Raghavan, D., \& Emekalam, A. (2001). Characterization of starch/polyethylene and starch/polyethylene/poly(lactic acid) composites. Polymer Degradation \& Stability, 72(3), 509-517. http://dx.doi.org/10.1016/S0141-3910(01)00054-4.

12. Michel, A. H., \& Hongbo, L. (2007). Morphology and properties of compatibilized polylactide/thermoplastic starch blends. Polymer, 48(1), 270-280. http://dx.doi.org/10.1016/j. polymer.2006.11.023.

13. Xiong, Z., Yang, Y., Feng, J., Zhang, X., Zhang, C., Tang, Z., \& Zhu, J. (2013). Preparation and characterization of poly(lactic acid)/ starch composites toughened with epoxidized soybean oil. Carbohydrate Polymers, 92(1), 810-816. PMid:23218370. http://dx.doi.org/10.1016/j.carbpol.2012.09.007.

14. Murillo, E. A., Cardona, A., \& López, B. (2010). Rheological behavior in the molten state and solution of hyperbranched polyester of fourth and fifth generation. Journal of Applied Polymer Science, 119(2), 929-935. http://dx.doi.org/10.1002/ app.32774.

15. Murillo, E, A., Vallejo, P. P., \& López, B. L. (2010). Characterization of hydroxylated hyperbranched polyesters of fourth and fifth generation. e-Polymer, 10, 1347-1358. http://dx.doi.org/10.1515/epoly.2010.10.1.1347.

16. Murillo, E. A., López, B. L., \& Brostow, W. (2011). Synthesis and characterization of novel alkyd-silicone hyperbranched nanoresins with high solid contents. Progress in Organic Coatings, 72(3), 292-298. http://dx.doi.org/10.1016/j. porgcoat.2011.04.019.
17. Murillo, E. A., Vallejo, P. P., \& López, B. L. (2011). Effect of tall oil acids content on the properties of novel hyperbranched alkyd resins. Journal of Applied Polymer Science, 120(6), 3151-3158. http://dx.doi.org/10.1002/app.33502.

18. Zagar, E., \& Zigon, M. (2011). Aliphatic hyperbranched polyesters based on 2, 2- bis(methylol) propionic acid Determination of structure, solution and bulk properties. Progress in Polymer Science, 36(1), 53-88. http://dx.doi. org/10.1016/j.progpolymsci.2010.08.004.

19. Zagar, E., Zigon, M., \& Podzimek, S. (2006). Characterization of commercial aliphatic hyperbranched polyesters. Polymer, 47(1), 166-175. http://dx.doi.org/10.1016/j.polymer.2005.10.142.

20. Vallejo, P. P., López, B. L., \& Murillo, E. A. (2015). Hyperbranched phenolic-alkyd resins with high solid content. Progress in Organic Coatings, 87, 213-221. http://dx.doi. org/10.1016/j.porgcoat.2015.06.007.

21. Mesías, R., \& Murillo, E. A. (2015). Hyperbranched polyester polyol modified with polylactic acid. Journal of Applied Polymer Science, 132(10), 41589-41597. http://dx.doi. org/10.1002/app.41589.

22. Liu, X., Khor, S., Petinakis, E., Yu, L., Simon, G., Dean, K., \& Bateman, S. (2010). Effects of hydrophilic fillers on the thermal degradation of poly(lactic acid). Thermochimica Acta, 509(1-2), 147-151. http://dx.doi.org/10.1016/j.tca.2010.06.015.

23. Obiro, C., Naushad, M., \& Suprakas, S. (2014). Inducing PLA/starch compatibility through butyl-etherification of waxy and high amylose starch. Carbohydrate Polymers, 112, 216-224. PMid:25129738. http://dx.doi.org/10.1016/j. carbpol.2014.05.095.

24. Racha, A. I., Khalid, L., \& Abderrahim, M. (2012). Improvement of thermal stability, rheological and mechanical properties of PLA and their blends by reactive extrusion with functionalized epoxy. Polymer Degradation \& Stability, 97(10), 1898-1914. http://dx.doi.org/10.1016/j.polymdegradstab.2012.06.028.

25. Li, J., Chen, D., Gui, B., Gu, M., \& Ren, J. (2011). Crystallization morphology and crystallization kinetics of poly(lactic acid): effect of N-Aminophthalimide as nucleating agent. Polymer Bulletin, 67(5), 775-791. http://dx.doi.org/10.1007/s00289010-0419-2.

26. Jang, W., Shin, B., Lee, T., \& Narayan, R. (2007). Thermal properties and morphology of biodegradable PLA/starch compatibilized blends. Journal of Industrial and Engineering Chemistry, 13, 457-464. Retrieved in 2016, July 26, from http://infosys.korea.ac.kr/research/tech/periodicals/view. php?seq $=581012$.

27. Ke, T., \& Sun, X. (2000). Physical properties of poly(lactic acid) and starch composites with various blending ratios. Cereal Chemistry, 77(6), 761-768. http://dx.doi.org/10.1094/ CCHEM.2000.77.6.761.

28. Huang, M., Yu, J., \& Ma, X. (2005). Ethanolamine as a novel plasticizer for thermoplastic starch. Polymer Degradation \& Stability, 90(3), 501-507. http://dx.doi.org/10.1016/j. polymdegradstab.2005.04.005.

29. Erdohan, Z., Cam, B., \& Turhan, K. (2013). Characterization of antimicrobial polylactic acid based films. Journal of Food Engineering, 119(2), 308-315. http://dx.doi.org/10.1016/j. jfoodeng.2013.05.043.

30. Garlotta, D. (2002). A literature review of poly (lactic acid). Journal of Polymers Environment, 9(2), 63-84. http://dx.doi. org/10.1023/A:1020200822435.

31. Teixeira, E. M., Campos, A., Marconcini, J. M., Bondancia, T. J., Wood, D., Klamczynski, A., Mattoso, L. H. C., \& Glenn, G. M. (2014). Starch/fiber/poly(lactic acid) foam and compressed foam composites. RSC Advances, 4(13), 6616-6623. http://dx.doi.org/10.1039/c3ra47395c. 
32. Lee, S. Y., \& Hanna, M. (2008). Preparation and characterization of tapioca starch-poly(lactic acid)-Cloisite NA + nanocomposite foams. Journal of Applied Polymer Science, 110(4), 23372344. http://dx.doi.org/10.1002/app.27730.

33. Muller, C., Pires, A., \& Yamashita, F. (2012). Characterization of thermoplastic starch/poly(lactic acid) blends obtained by extrusion and thermopressing. Journal of the Brazilian Chemical Society, 23, 426-434. http://dx.doi.org/10.1590/ S0103-50532012000300008

34. Wang, N., Yu, J., Chang, P., \& Ma, X. (2008). Influence of formamide and water on the properties of thermoplastic starch/poly(lactic acid) blends. Carbohydrate Polymers, 71(1), 109-118. http://dx.doi.org/10.1016/j.carbpol.2007.05.025.
35. Ning, W., Xingxiang, Z., Na, H., \& Jianming F. (2010). Effects of water on the properties of thermoplastic starch poly(lactic acid) blend containing citric acid. Journal of Thermoplastic Composites Materials, 23, 19-34. http:// dx.doi.org/10.1177/0892705709096549.

36. Uppuluri, S., Morrison, F. A., \& Dvornic, P. R. (2000). Rheology of dendrimers. 2. Bulk polyamidoamine dendrimers under steady shear, creep, and dynamic. Macromolecules, 33(7), 2551-2560. http://dx.doi.org/10.1021/ma990634u.

Received: July 26, 2016

Revised: Apr. 04, 2017

Accepted: Apr. 27, 2017 